\title{
The Fucntions of Space in Film Shot
}

\author{
Xiaofeng Zhang \\ Beijing Film Academy \\ Beijing, China
}

\begin{abstract}
Screenwriters consider of the story world and write on the pictures to construct the imaginary world. Then the every presence of space in one film is designed by director, cameraman, art designer, sound engineer. They all give the space special significance which narrate the whole story. The thesis takes space that presents in film shot as research objects, taking HER, DEVILS ON THE DOORSTEP, LALA LAND AND CLOUD ATLAS as examples. Space in film will not only be the background, scene or spectacle, but we will analyse the spatial signification and spatial aesthetics that a shot can have.
\end{abstract}

Keywords-Spatial Presence; Spatial Narrative; Spatial Signification; Spatial Aesthetics

\section{INTRODUCTION}

People can't find two pieces of leaves are the same in the world, as the same we can't find the absolutely same space in two shots. People can not step into the same river two times, then people also can't step the same space in the screen. [1]The feeling of space from the screen is created by framing, composition, perspective and visual hallucination in spectaters' eyes . Hereon, we will not discuss how space is created in film shot, but the impression and meaning which causing sense of space will be discussed. Space is entirety, including sound, light, colour, utensils and character. All the elements constitute the holonomic spcace that can create the scense of space.

Elements of space means what there are in the space. Genelly, point, line and plane are the basic parts of space. but space is limitted by the real substance and materiel. What in the space of shot is the detail materiel, such as prop, light, the motion of roles and so on. There are two kinds of elements in space, the essential and the creative. The former refers to the materiel which sonstructs the conception of the place, such as if we see road, there must be some materiel that forms the road. It means where and what kind of place and eviriment the plot will happen in. The craetive means that the elements selected by the creaters will help the purpuse of narration, a kind of creation and uniqueness. There are also two kinds of condition of elements: nature, decribing objectively and emotional, expressing subjectively.

In reality, people keep interaction with spaceon initiative. While in film, character, plot, relationship and space are lack of initiative. The creater cast the real contacts between people and space in screen. Space in shot is audiovisual symbols which can reflect the real contact. So this article will disscuss how space works as 'given signification'[2] in narrative and aesthetics.

\section{SPATIAL NARRATIVE}

Space in shot has three functions in narrating stories, working as the background, shaping the character and promoting the plot.

\section{A. Working as Background}

Every space is selected and designed uniquely, is the 'container'of characters and plots. The space in shot can directly show the aoudiences the roles will act in what kind of places. Places means a certain location which includes different contents and structures, performing the distinctions. There are some rules limitting the roles in life, work, emotion and relatinship. The most important is the place gives the roles unique identity in special space. With the identity, roles start to act in the place and narrate the plot."Fig. 1"
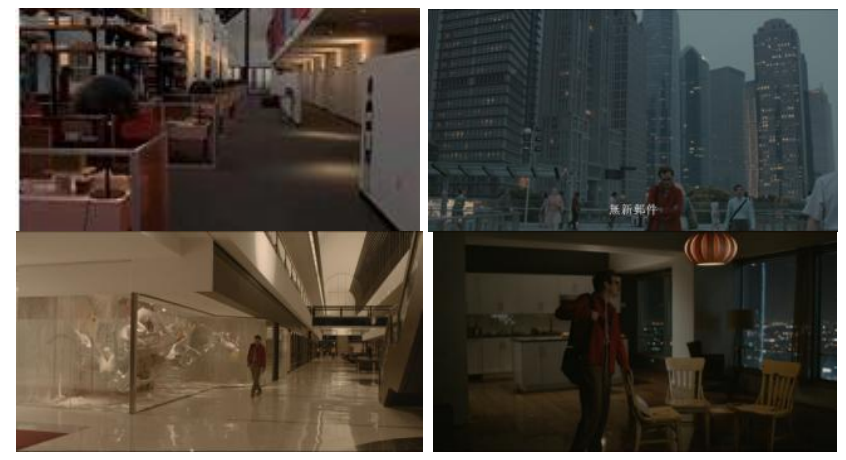

Fig. 1. Three opening space in $H E R$, office, city, apartment.

The regular lines meaning monotonous, future and lonely construct every space. We can see Theodor is surrounded by the lines. What's more, he stays in a little darkness, just like his sad mood. The first three space represents different circumstances, showing Theodor's living condition. Then we will vivid know that the roles and plot will happen in a detail city and the unique atmasphere. As the background, the place becomes a container in which the time can develops.

\section{B. Shaping Characters}

In real life, we live in time and space. People trasnsform the space and space affects people's life. We call it interaction, revealing the civilizations of human beings. But I think that space is producted by civilizitions just like a kind of products, shared by present people who live in it. So the space must carry the culture and sentiments of people. Then in a film, space showed in shot has to reveal the actual above feeling. 
Taking DEVILS ON THE DOORSTEP as an example, there is a plot about inquest. The worn-out adobe room is separated into two by a piece of white cloth. The uniqueness is that two group of roles stay in the separated rooms.

1) Ma Dasan and The Farmers' Space: Seven acters, aswarm; bright background with shabby curtain and thick rope; farmers stay in high position, playing as inquisitionists. We can see the complex moods reflecting by the space. Bighrness implies justice, while the huddle implies farmers' nervousness and fear, especially the light passing through the holes in the curtain beacons the rocking rope, just like their gallows. On the other hand, they become huge shadows on the cloth, implying invisible and powerfull, showing panic and unknown from the other side. "Fig. 2"
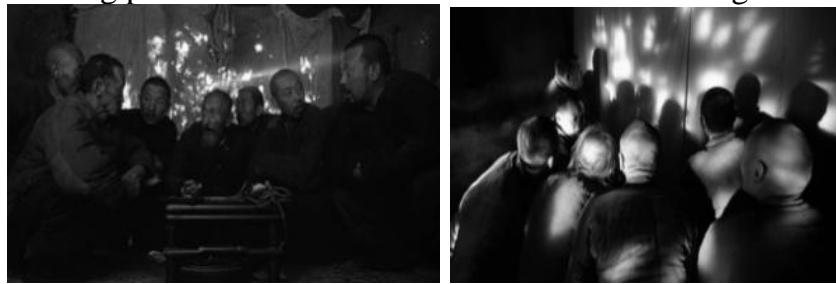

Fig. 2. The farmers' space.

2) Japanese Soldier and Chinese Translator's Space: Two acters wih mussy farm tools, implying the manipulated fate ; Lower position and darkness, inplying they are being interrogated and filled with fear. So they can see huge black cucoloris in their eyes. But the space is a little wilder than the farmers', implying the parochial militarism with death. Jiangwen narrows the shot and scene, shrinking the space. Then the space means the stubborn will and awkward condition of the Chinese translator. The compare shows the inverse psychologies of the two. "Fig. 3"
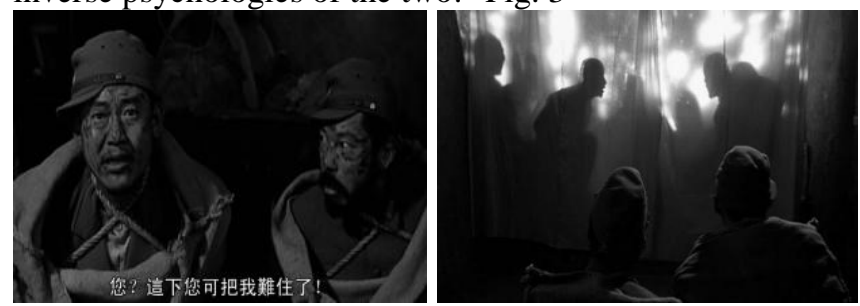

Fig. 3. Japanese soldier and chinese translator's space.

From the example, we can see that space is personated with characters's emotion. Off the screen, we follow our thoughts and likes to keep in some conditions in real space. On the screen, the space in shot is reflecting the conditons people have made in their life and tring the best to turn it in the audio-visual Languages, which can be discerned by the viewers.

\section{Promoting The Plots}

Plot is process that how things happen, essentially means the time ticks away in changing space.

1) New Space: A new space broadens the charaters' sphere of activities. At same time, new space gives the them objective and impersonal rules to obey. If charaters want to complete their tasks, they must destroy and rebulid the rules. Two results:peacefull or rebellious. Especially in road movies, new space continues to appear, the charaters come through from different places, experience different people and plot, then they changing their thoughts and minds with the continuous new space.

2) Changing Space: The duration of one film is limited, then the space is numerable. Characters leave and return the same space, performing different plots and psychologies. Space appears as consequent result in different periods, which means the same space keep changing into different appearence in differernt conditions. Then some changes in the space will show the diversifications of characters. From "Table I", we can see some delicate changes in LALALAND, in Sebastian's parlour.

TABLE I. DisTinctions BETWEEN FIRST TIME AND THE SECOND

\begin{tabular}{|l|l|l|}
\hline \multicolumn{1}{|c|}{ Changing Elements } & \multicolumn{1}{c|}{ First } & \multicolumn{1}{c|}{ Second } \\
\hline whole & diorder & order \\
\hline position & $\begin{array}{l}\text { Piano: center } \\
\text { wooden chair: high }\end{array}$ & $\begin{array}{l}\text { Piano: side } \\
\text { wooden chair: low }\end{array}$ \\
\hline light & weak & strong \\
\hline
\end{tabular}

In the first time, the whole space is in a muddle, implying Sebastian's situation, holding unrealistic dream and having nothing to do. In the second time, after his sister's taunt, the wooden chair as the metaphor of the jazzy dream stays in the corner of the wall on the floor. All the changes implies the changes in his mind, still holding the dream but falling into inner contradiction.
First

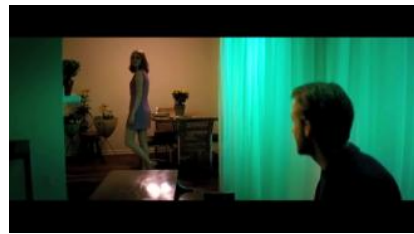

Third

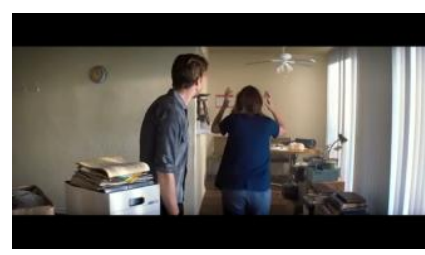

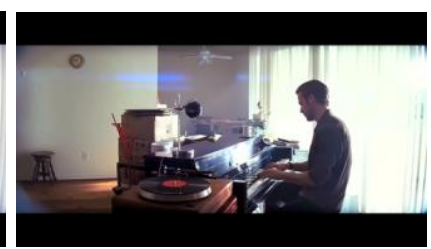

Second

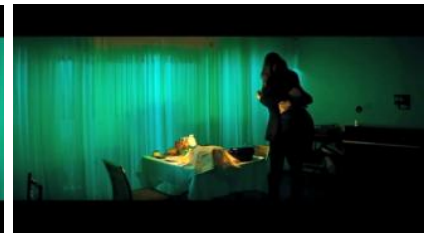

Fourth
Fig. 4. The different changes in different times.

From the "Fig. 4", we can see the angle of the shot is immobile between the second and the third, because of their sweet love, the light of the room, ornament of the background have changed, showing the changing emotions of Sebastian. Comparing the third and fourth, the atmosphere is the same, the couple still love each other. While the angle of shot has changed, we see the opposite wall, just like we reknow Sebastian from a new side. What's the improtant is that the wooden chair is no more here in the space, and 
dining-table displaces the piano in center, seeming to tell us Sebastian's compromise.

There is different fuction in the four times, the changing elements of the space strengthens the dramatic conflict. Everything in the world keeps changing everytime, time is going and space is changing. The changes imply the truth of movement, then people can feel their life in time and space.

\section{SPATIAL SIGNIFICATION}

The study of Human Geography thinks that 'the culture of human make use of geography to give the special space special signification'[3]. Human is working on the geography for thousands of years, interacting with each other. It means human know the world and truth from reforming the geography. So in films, space is given the similar signification. Receivers of the signification are viewers who get the points through the characters and plots. So Spatial Signification means that the special space helps the story to narrate more fluently. We partion two parts:general and aesthetic

\section{A. General ideographic function}

Its aim is to reveal the theme of the story. Space can't narrate the details of signification like any roles in the story. Sometime the theme and emotion can't telled by languages, but they can be felt by composition of shot, incluing the most important part of space. So the compared composition will be the best way the impress viewers:similar and dissimilar with atmosphere.

1) Similar: The design of space must be on purpuse, except for the physical function, the selected elements are sign of some tones that can show narrative theme. In this conditon, there is a positive correlation between space and theme, theme gets strengthened. "Fig. 5"
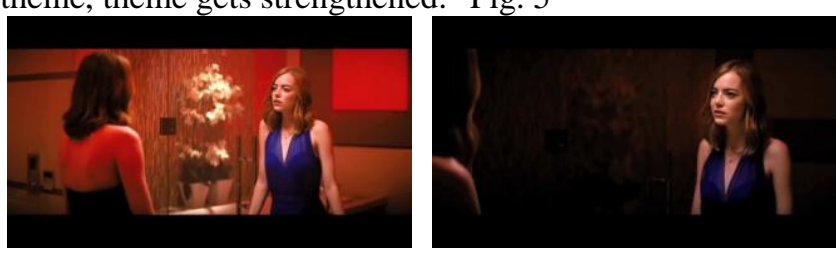

Fig. 5. LALA LAND Mia in mirror.

As above pictures, Mia escapes into the washing room from the noisy party for his failure. The space is narrow and full of kermesinus with a huge mirror(comparation with the former one in Mia's flat), Mia and we can clearly her front image from the mirror, she is gazing herself. Only she stays in the room, she can keep personal and quiet. Kermesinus implies her saddness. So the atmosphere is matched with the mood witout saying a words. Then the light become darkness, leaving her image lonely and amplifying her emotion.

2) Dissimilar: There are distinctions between space and theme, they are keeping in inverse ratio, which space amplifying the theme in the contrary way. "Fig. 6"
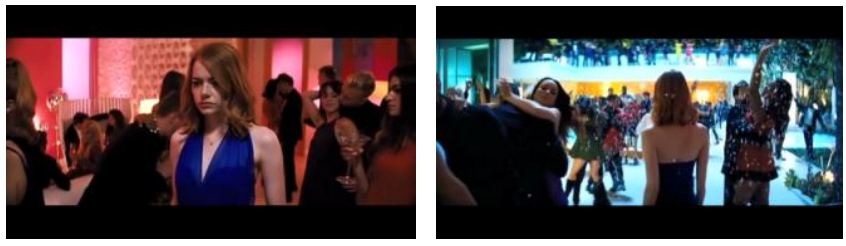

Fig. 6. LALA LAND Mia gets out of washing room

Mia passes through dangcing young people in slow shot Even she gets out of the Kermesinus, she goes into another group of crazy people in snow. She is single among people, the crazy atmosphere is contrary while serve as a foil to her loneliness. In the same time, the directer take a way, slow motion, to allow audience feel her mind. It runs counter to the the party, forming contrast.

\section{B. Aesthetic Function}

Aesthetic function is the philosophy hidden in general ideographic function, is the cognition that creaters summarize from their life, is after the surface of daily life.

Symbolization is the best way to express the philosophy, it is denited as 'Describing something indirectly, while describing it according the interdependency between two things with the help of association'[4]. Space is the aesthetic object which can be seen and felt. Esthetics is the noumenon of symbolization. Space works as signifiant which can lead to designatum, then the condition of real life will be manifested.

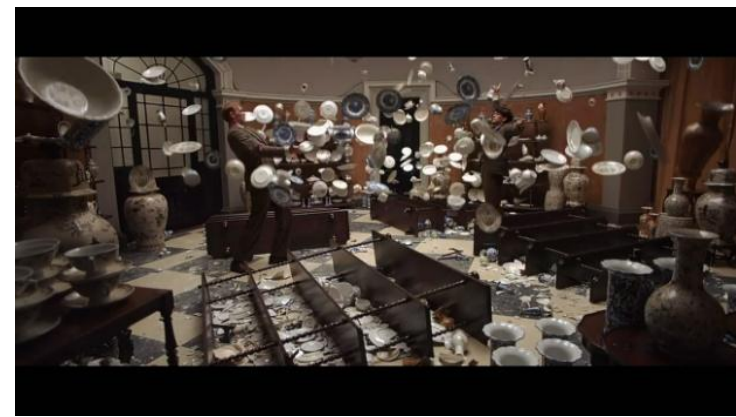

Fig. 7. CLOUD ATLAS Throwing ceramics.

For example, Frobisher and Smith are throwing the ceramics in a circular room. First, we can get nothing if we get ride of symbolization. Circle is usually meant flawlessness and metempsychosis, implying their love and renascence. Second, they stay in the center of the room, as if they can control their life. Third, ceramics is the main element of the space, why ceramics?Because ceramics is relavent with fragility and weakness, implying that their homosexual love is easy to be destroyed. The three construct the whole symbolization of life, esthetics of foreordination.

\section{CONCLUSION}

Zhuang Zhou said 'Life in the world, as the white pony gaps suddenly and already'[5]. Space is at the same dimension as time. During the development of western philosophy, ancient Greek philosophers, Hesiods, talks about Void Theory, Plato talks about present and ideal world. Until 
Martin Heidegger, Henri Lefebvre and Michel Foucault, they develop the morden conception of space. Space and time, the former can be seen, the latter can be felt, construting the life.

As the turn of knowing about space and time, narratology turns to spatial narrative, exploring how space help narrating in content and form. Especially in film theroy, space is the most important part to study. Therefore, space will never only be the background of story, it is full of knowledge, civilization and philosophy of life. Film is just a story consisted by plots, but we can get more that.

\section{REFERENCES}

[1] Pan Xiutong, Sense of Space in Film, Literrature and Art Research, 1983. 03.

[2] Mike Krone, Cultural Geography, University Press, 2000.

[3] Mike Krone, Cultural Geography, University Press, 2000.

[4] Wang Xijie, Chinese Rhetoric, Peking University Press, 1983. 12.

[5] Zhuang Zhou, Zhuang Zi. Xiao Yaoyou, Xinhua press, 2015. 